\title{
Cerebellar anatomy as applied to cerebellar microsurgical resections
}

Anatomia cerebelar aplicada à microcirurgia cerebelar ablativa

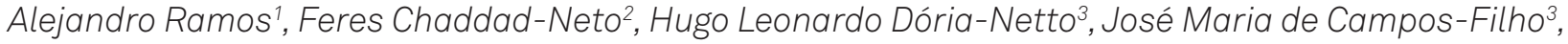
Evandro Oliveira ${ }^{4}$

\begin{abstract}
Objective: To define the anatomy of dentate nucleus and cerebellar peduncles, demonstrating the surgical application of anatomic landmarks in cerebellar resections. Methods: Twenty cerebellar hemispheres were studied. Results: The majority of dentate nucleus and cerebellar peduncles had demonstrated constant relationship to other cerebellar structures, which provided landmarks for surgical approaching. The lateral border is separated from the midline by $19.5 \mathrm{~mm}$ in both hemispheres. The posterior border of the cortex is separated $23.3 \mathrm{~mm}$ from the posterior segment of the dentate nucleus; the lateral one is separated $26 \mathrm{~mm}$ from the lateral border of the nucleus; and the posterior segment of the dentate nucleus is separated $25.4 \mathrm{~mm}$ from the posterolateral angle formed by the junction of lateral and posterior borders of cerebellar hemisphere. Conclusions: Microsurgical anatomy has provided important landmarks that could be applied to cerebellar surgical resections.
\end{abstract}

Key words: cerebellum, anatomy, neurosurgery.

\section{RESUMO}

Objetivo: Definir a anatomia do núcleo denteado e dos pedúnculos cerebelares, demonstrando a aplicação dos marcos anatômicos em cirurgias cerebelares. Métodos: Foram estudados 20 hemisférios cerebelares. Resultados: A maioria dos núcleos denteados e pedúnculos cerebelares demonstraram relação anatômica constante com outras estruturas cerebelares, fato que proporcionou o estabelecimento de marcos anatômicos específicos a serem utilizados em acessos cirúrgicos. O bordo lateral do núcleo denteado é separado da linha média em 19,5 mm em ambos os hemisférios cerebelares. O bordo posterior do córtex é separado do segmento posterior do núcleo denteado por 23,3 mm. O bordo lateral do córtex é separado do bordo lateral do núcleo por 26 mm e o segmento posterior do núcleo denteado é separado por 25,4 mm do ângulo posterolateral, que é formado pela junção dos bordos lateral e posterior do hemisfério cerebelar. Conclusões: 0 estudo da anatomia microcirúrgica proporcionou o estabelecimento de marcos anatômicos importantes que podem ser utilizados durante cirurgias cerebelares ablativas.

Palavras-Chave: cerebelo, anatomia, neurocirurgia.

The cerebellum is an exquisite anatomic structure within the human brain, which needs to be considered from the surgical standpoint because of its functional importance and common pathologies that affect this area ${ }^{1}$. It is possible to reach the cerebellum avoiding damaging neural structures by approaches which target tentorial, petrosal, or suboccipital surfaces. Each has its microsurgical particularities in order to reach the desired region and preserve neural structures².

In this article, we have presented the microsurgical anatomy of the suboccipital and supracerebellar approaches to the cerebellar surfaces using comprehensives anatomic and functional relations with the final objective of performing better operations with less damage to the cerebellar nucli and important deep pathways.

\section{METHODS}

The dentate nucleus, cerebellar peduncles and their relationship with others cerebellar structures were studied in 20 adult cerebellar hemispheres, 12 male and 8 female corpses, obtained from São Paulo death verification service using X3 to X40 magnifications.

${ }^{1}$ Neurosurgeon Fellow of Microanatomy Laboratory in Hospital Beneficência Portuguesa of São Paulo, São Paulo SP, Brazil;

${ }^{2}$ Neurosurgeon of Instituto de Ciências Neurológicas (ICNE) and Hospital Beneficência Portuguesa of São Paulo; Coordinator of Microanatomy Laboratory in Hospital Beneficência Portuguesa of São Paulo, São Paulo SP, Brazil;

${ }^{3}$ Neurosurgeon of Instituto de Ciências Neurológicas (ICNE) and Hospital Beneficência Portuguesa of São Paulo, São Paulo SP, Brazil;

${ }^{4}$ Neurosurgeon of Instituto de Ciências Neurológicas (ICNE) and Hospital Beneficência Portuguesa of São Paulo; Director of Microanatomy Laboratory in Hospital Beneficência Portuguesa of São Paulo, São Paulo SP, Brazil.

Correspondence: Hugo Leonardo Dória Netto; Instituto de Ciências Neurológicas; Praça Amadeu Amaral 27 / 5 a andar; 01327 -010 São Paulo SP - Brasil; E-mail:hldoria@hotmail.com

Conflict of interest: There is no conflict of interest to declare.

Received 11 July 2011; Received in final form 07 December 2011; Accepted 14 December 2011 


\section{Histological and functional considerations}

The cerebellum has a special cytoarchitecture, which makes it unique ${ }^{3}$. Histologically the cortex presents three layers of cells that involve a central white substance. These layers include the molecular, the Purkinje, and the granular cells. The only efferent cells are the Purkinje ones that end in the central nucleus playing an inhibition action. The layer in contact with the white substance is constituted of granular cells. Two different kinds of afferents cerebellar fibers arrive to the cerebellar cortex: the fibers that interconnect the caudal olives with the purkinje cells (olivocerebellar tract) and the myelinic fibers that come to an end in the granular layer (pontocerebellar, spinocerebellar, and vestibulocerebellar tracts) ${ }^{4}$.

The Purkinje cells are the main afferents of the cerebellar nucleus and most of the efferent fibers from the cerebellum come from these nuclei; there are four nuclei in the cerebellum, which includes from medial to lateral, the fastigial, globose, emboliform, and dentate nucleus ${ }^{1,2}$. The cerebellum can be longitudinally subdivided as follows: a midline zone, containing axons projecting to the fastigial nucleus and connecting with the vestibular nucleus and reticular formation; an intermedial zone, projecting to the nucleus interpositus (globose and emboliform) and connecting with the contralateral red nucleus and thalamic nucleus with impulses to the cerebral cortex; and a lateral zone, containing axons to the dentate nucleus, which course to the contralateral thalamic nucleus that transmits impulses to the cerebral cortex. Functionally, this nucleus controls a different type of movements: the fastigial controls posture and gait; the nucleus interpositus controls segmental reflexes and assists the initiation of movements; and the dentate nucleus controls fine dexterity. One of the main important features of the cerebellum is its control on the automatic excitation of antagonist muscles at the end of the movement with simultaneous inhibition of the agonist muscles, which initiated the movement ${ }^{5}$.

Afferent fibers from the brain stem project to the cerebellum by the inferior, middle, and superior cerebellar peduncle. Afferent fibers from the medulla carry the anterior and posterior spinocerebellar tract that project to the cerebellum by the superior and inferior cerebellar peduncles. The pontine fibers from the pontine nucleus project to the cerebellum by the middle cerebellar peduncle. The cerebello vestibular fibers, from the vestibular nucleus, project to the cerebellum by the inferior cerebellar peduncle. Most of the efferent fibers from the cerebellum go to the superior cerebellar peduncle $^{4,5}$.

\section{Anatomic considerations}

Anatomically, the cerebellum can be considered as a three-surface triangle: tentorial, suboccipital, and petrosal surfaces $^{2}$. The posterior-superior or tentorial surface is the most regular of all surfaces. It is surrounded superiorly by the tentorium and posteriorly limited by the lateral sinus and laterally by the sigmoid sinus; the division between the lateral and sigmoid sinus is located at the junction with the superior petrosal sinus. The tentorial surface has two incisures in the midline: the anterior one is related to the brain stem and the posterior incisure is related to the falx cerebelli. There are two fissures on the tentorial surface, which divide this surface into anterior, middle, and posterior parts. The anterior fissure is the tentorial one and the posterior fissure is the postclival one. The vermian surface is the most superior part of this surface.

The posterior inferior or suboccipital surface is located down the lateral sinus and inferomedially to the sigmoid sinus ${ }^{6}$. The falx cerebelli extends from the tentorial surface above to the inferior part of the middle suboccipital surface, the falx overlies a vertical depression that is medially formed by the vermis, laterally by the medial aspects of the cerebellar hemispheres and continues inferiorly with the vallecula cerebelli. When it is viewed from a posterior position, the only part of the vermis that is uncovered on this surface is at the side where the pyramid meets the uvula, located down this surface. There are two fissures on the suboccipital surface that divide it in superior, middle, and inferior parts. The superior fissure is the petrosal and the inferior is the suboccipital one. The tonsils are the most prominent hemispheric structures of the suboccipital surface, located inferomedially. The tonsils are ovoid structures, which have a middle vertical size of $13.5 \mathrm{~mm}$ (range from 10 to $18 \mathrm{~mm}$ ) and a wide size of $7.8 \mathrm{~mm}$ (range from 5 to $10 \mathrm{~mm}$ ). The tonsils have an implantation base to the suboccipital surface of the cerebellum at the superior lateral border and they are superoanteriorly related to the inferior medullary velum and tela choroidea, laterally to the biventral lobule, superolaterally to the tellovelotonsilar cleft, posteriorly and inferiorly to the cistern magna, medially

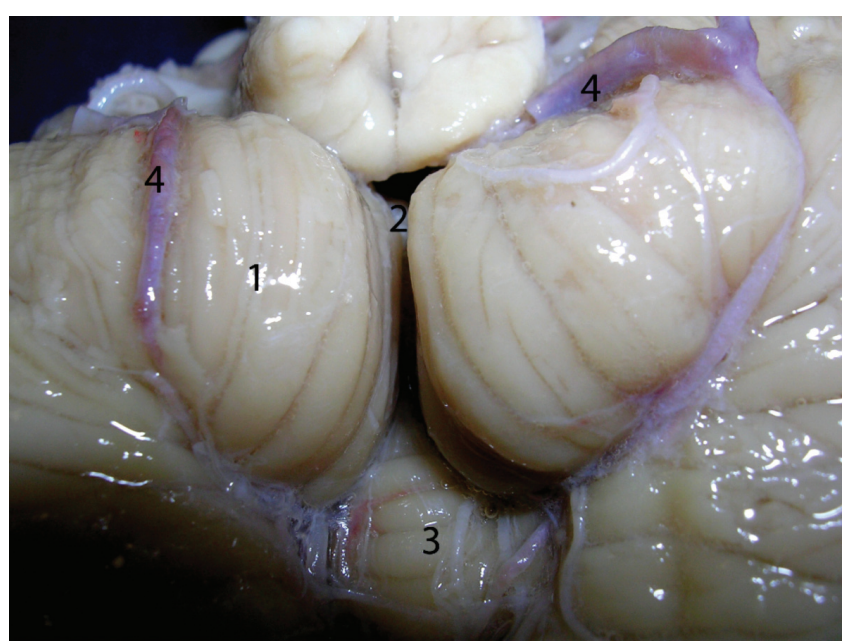

Fig 1. Suboccipital surface view. The vallecula extends between the tonsils and communicates through the foramen of Magendie with the fourth ventricle. 1: tonsil; 2: vallecula; 3 : uvula; 4: PICA. 
to the vallecula cerebelli, superomedially to the uvula, and anteriorly to the medulla ${ }^{2,7}$ (Fig 1).

The tentorial surface is related to the superior cerebellar artery, which arises at the pontomesecenphalic junction, encircles the brain stem, and is directed medially and backward to the tentorial surface. The artery runs as a single trunk up to the lateral pontomesencephalic segment, where the artery commonly divides into two trunks: the superior runs within the mesencephalic fissure, passes down to the inferior colliculus, and continues posteromedially to the superior half of the fourth ventricle. The inferior trunk also runs within the anterior part of the mesencephalic fissure, but shortly, the artery turns superolaterally to the tentorial surface. The branches of these trunks give off the precerebellar arteries which course medially from the mesencephalic fissure to the superior peduncle and dentate nucleus. The anterior inferior cerebellar artery (AICA) arises at the anterior pontine level; passes around the cerebellopontine fissure and goes to the pontomedullar segment, dividing into two trunks. The rostral trunk passes between the facial and vestibulocochear nerves and around the superior part of the flocculus to supply the middle peduncle. The caudal trunk passes below the flocculus near the IX and X nerves to supply the petrosal surface. The posterior inferior cerebellar artery (PICA) arises at the anterior medullary level, passes around the medulla, crosses the inferior cerebellar peduncle, enters the cerebellomedullar fissure, where it is closely related to the inferior half of the fourth ventricle, and exits the fissure to supply the suboccipital surface ${ }^{8}$.

The veins of the cerebellum are divided into superficial and deep. The superficial group is divided into tentorial, petrosal, and suboccipital veins. The tentorial surface veins are drained by the superior hemispheric and vermian veins, which empty into the vein of Galen and the tentorial sinuses. The petrosal surface veins are drained by the anterior hemispheric veins, which empty mainly into the superior petrosal sinus. The suboccipital surface veins are drained by the inferior hemispheric and inferior vermian veins, which commonly empty into the tentorial sinuses. The deep veins are divided into: the vein of the cerebellomesecephalic fissure that is related to the superior half of the roof of the fourth ventricle; the vein of the cerebellomedullary fissure that is related to the inferior half of the roof; and the vein of the cerebellopontine fissure that is related to the laterals walls of the fourth ventricle. The veins of the three peduncles also course within these fissures.

The vein of the superior cerebellar peduncle courses in the cerebellomesencephalic fissure; the one from the middle cerebellar peduncle courses in the anterior part of the cerebellopontine fissure; and the one from the inferior cerebellar peduncle courses in the cerebellomedullary fissure. In general terms, the vein of the cerebellomesencephalic fissure and the vein of the superior cerebellar peduncle drain into the vein of Galen; the veins of the cerebellomedullary fissure and inferior cerebellar peduncle drain into the petrosal veins; the veins of the cerebellopontine fissure and of the middle cerebellar peduncle also drain through the petrosal ones ${ }^{3,6}$.

\section{RESULTS}

After our research, we could conclude that the lateral border of the dentate nucleus is separated from the midline by an average of $19.5 \mathrm{~mm}$ in the right hemisphere (range - from 17 to $21 \mathrm{~mm}$ ) and $19.5 \mathrm{~mm}$ in the left ones (range - from 14 to $23 \mathrm{~mm}$ ), as seen in Fig 2.

The dentate nucleus has a unique shape. It is oriented in craniocaudal direction and from lateral to medial. It is helpful to consider the dentate nucleus with upper and lower surfaces, and three segments. The upper surface is related medially to the superior cerebellar peduncle and faces the vermis at the junction of the cumen and declive. The upper surface is bordered laterally, anteriorly, and posteriorly by the fibers of the middle cerebellar peduncle. At the basal surface, the dentate nucleus is related anteriorly to the caudal segment of the flocculus, medially to the telovelotonsillar cleft and posteromedially to the superior pole of the tonsil and the lateral border of the uvula in its posterolateral third (Fig 3).

The distance from the posterior extreme of the uvula to the posterior segment of the dentate nucleus is on average $16.2 \mathrm{~mm}$ (range - from 13 to $20 \mathrm{~mm}$ ). The posterior border of the cortex is separated on an average of $23.3 \mathrm{~mm}$ (range from 20 to $29 \mathrm{~mm}$ ) from the posterior segment of the dentate nucleus; the lateral border of the cortex is separated on an average of $26 \mathrm{~mm}$ (range - from 15 to $32 \mathrm{~mm}$ ) from the lateral border of the nucleus; and the posterior segment of the dentate nucleus is separated on an average of $25.4 \mathrm{~mm}$ (range

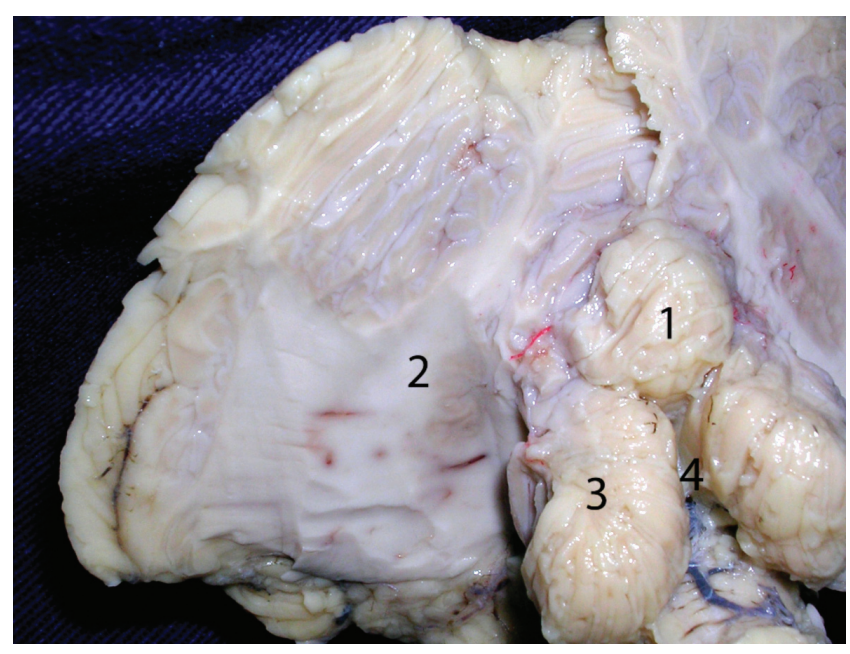

Fig 2. Basal surface of the cerebellum. The left and right cerebellar hemispheres have been removed to expose the dentate nucleus and its relationship with the tonsils. 1: uvula; 2: dentate nucleus; 3: tonsil; 4: vallecula. 
- from 17 to $31 \mathrm{~mm}$ ) from the posterolateral angle, which is formed by the junction of the lateral and posterior borders of the cerebellar hemisphere (Fig 4).

The distance from the inferior pole of the tonsil to the level of the basal surface of the dentate nucleus is approximately $19.4 \mathrm{~mm}$ on the right side (range - from 18 to $22 \mathrm{~mm}$ ) and $19.4 \mathrm{~mm}$ (range - from 16 to $25 \mathrm{~mm}$ ) on the left one, as seen in Figs 5 and 6.

From the basal suboccipital surface to the tentorial one, the association fibers of the white matter start to form thick laminae or lobular peduncles at $10 \mathrm{~mm}$ (range - from 0.8 to $1.4 \mathrm{~mm}$ ) from the superior pole of the tonsil. The cortex of the cerebellum is not divided into gyri, but instead into numerous folia. According to Lange, the cortical portion of the cerebellum forms about $67 \%$ of the total surface area. In this study, the lateral border of the cerebellar cortex is separated on an average of $14.8 \mathrm{~mm}$ (range - from 10 to $25 \mathrm{~mm}$ ) at the level of the dentate nucleus, from the subcortical white matter or lobular peduncle; and the posterior border of the cerebellar cortex is separated on an average of $15.4 \mathrm{~mm}$ (range - from 0.8 to $24 \mathrm{~mm}$ ), from the subcortical white matter (Fig 7).

\section{DISCUSSION}

From a surgical perspective, it is helpful to consider the cerebellar hemispheres as a three-component structure that can be divided into median, paramedian, and lateral zones. The median zone extends from the lateral border of the vermis to the lateral one of the dentate nucleus; the paramedian zone extends from the lateral border of the dentate nucleus to the junction of the white matter substance and the cortex;

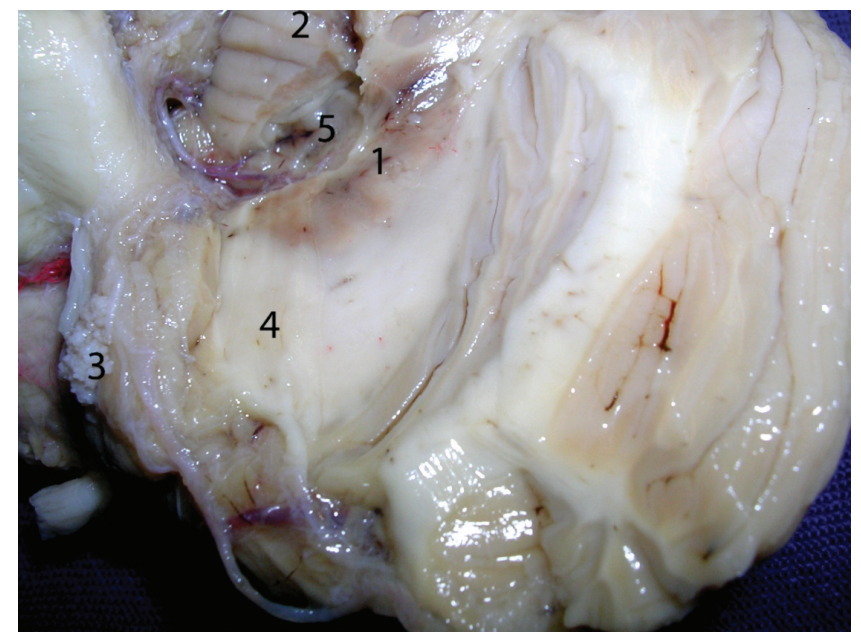

Fig 3. Basal surface of the cerebellar hemisphere. The left cerebellar hemisphere and the tonsil have been removed to expose the uvula and their relationship with the superior pole of the tonsil and the dentate nucleus. 1: dentate nucleus; 2: uvula; 3: flocculus; 4: middle cerebellar peduncle; 5: superior pole place of the tonsil after removed. and the lateral zone is the cortex. This is based on similar structures related in each zone $e^{9}$

The cerebellum is connected to the brain stem by three large cerebellar peduncles, each peduncle displays a special shape that creates a particular stratification in the cerebellar hemisphere; the relations between the peduncles, the cerebellar cortex and the cerebellar nuclei are extremely important to access the cerebellum ${ }^{10}$.

The white matter of the cerebellum forms a central core, which receives afferent fibers from the cortex; these fibers create laminae of white matter that comes from the cortex to the central core. The pathways and the central core have variable shapes in each cerebellar hemisphere, but the

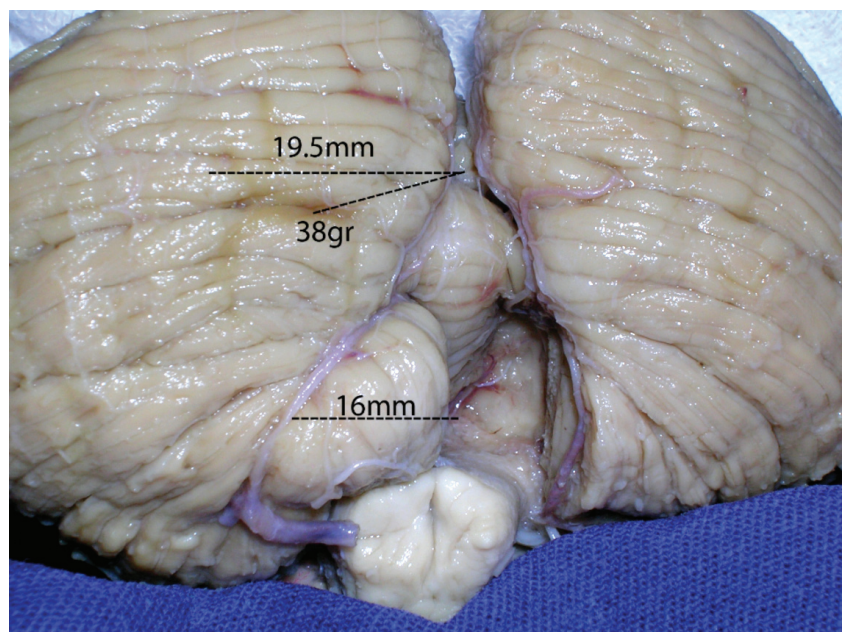

Fig 4. Suboccipital surface view of the cerebellum. Notice that the distance from the middle line to the lateral border of the dentate nucleus is $19.5 \mathrm{~mm}$ and $38^{\circ}$ is the angle of separation from the middle line to avoid the dentate nucleus during the surgical resections. Also, the distance from the middle line to the lateral border of the tonsil is approximately $16 \mathrm{~mm}$.

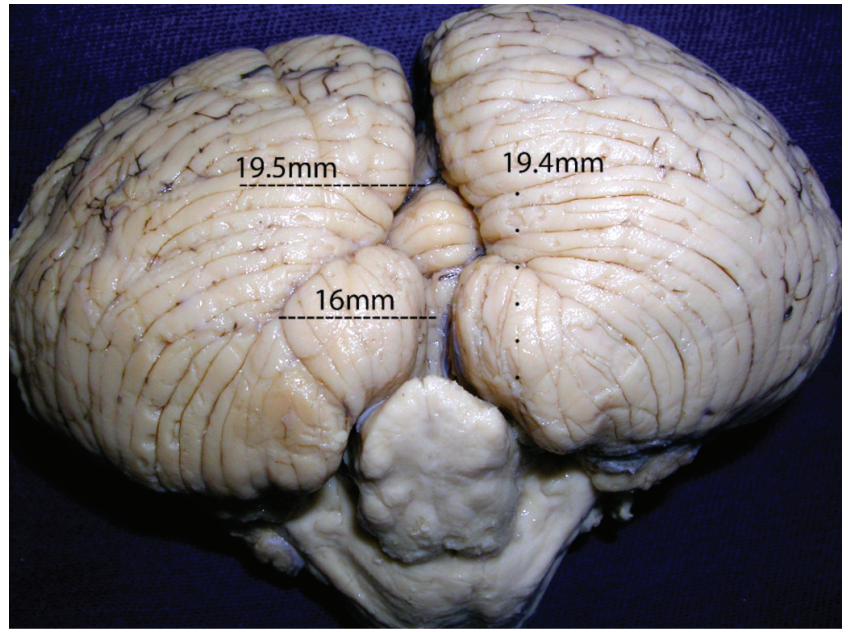

Fig 5. Suboccipital surface view of the cerebellum. The distance from the middle line to the lateral border of the dentate nucleus is approximately $19.5 \mathrm{~mm}$ and the distance from the inferior pole of the tonsil to the level of the basal surface of the dentate nucleus is approximately $19.4 \mathrm{~mm}$. Also, $16 \mathrm{~mm}$ is the distance from the middle line to the lateral border of the tonsil. 


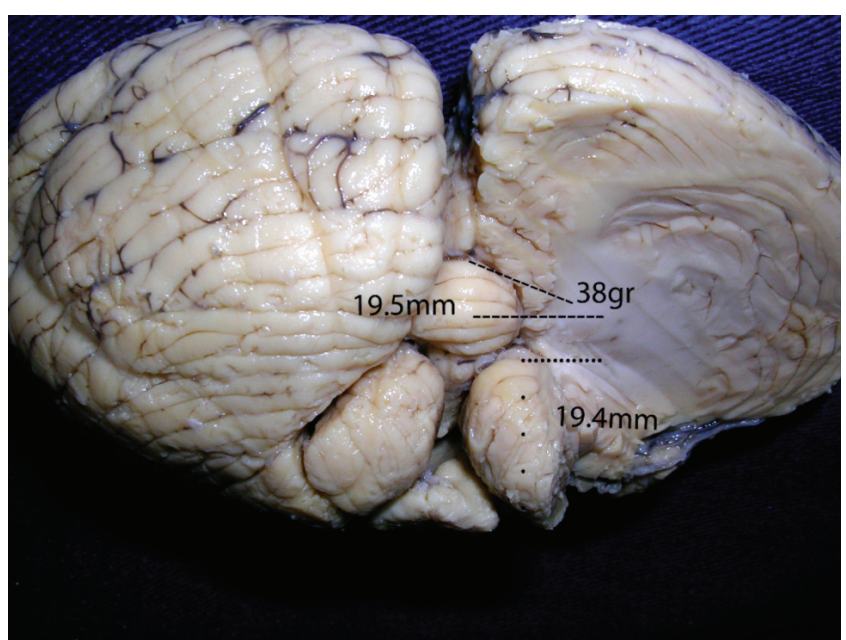

Fig 6. The right cerebellar hemisphere has been sectioned to show the different relationships of the dentate nucleus to the nearby structures. The distance from the lateral border of the dentate nucleus to the middle line is on an average of $19.5 \mathrm{~mm}$; the distance from the inferior pole of the tonsil to the basal surface of the dentate nucleus is on average $19.4 \mathrm{~mm}$ and $38^{\circ}$ is on average the angle of separation from the middle line to lateral border of the dentate nucleus.

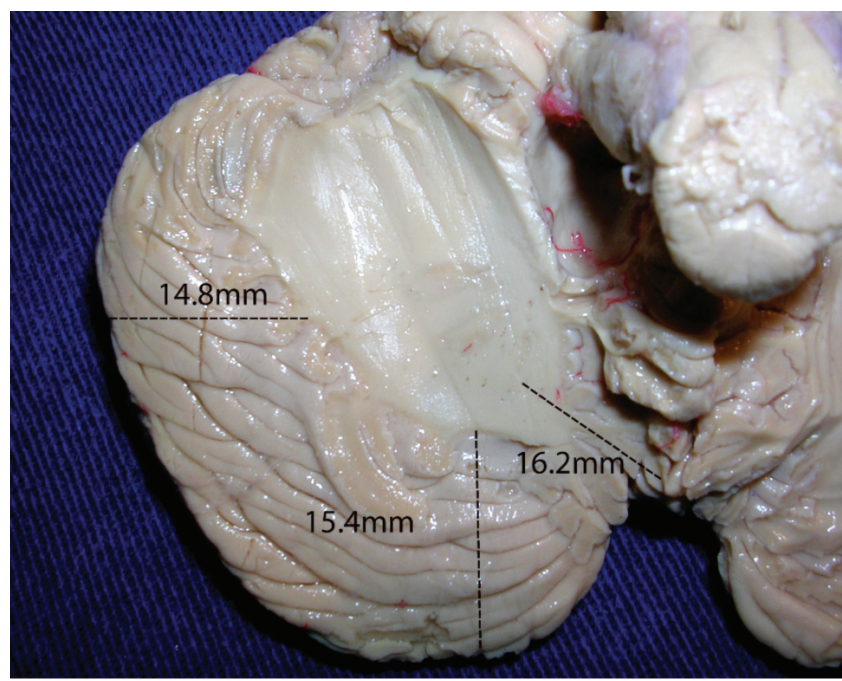

Fig 7. Basal surface view of the right cerebellar hemisphere. The cerebellar hemisphere has been partially sectioned to show the cortex and the subcortical area at the level of the dentate nucleus. The lateral border of the cerebellar cortex is separated on an average of $14.8 \mathrm{~mm}$, at the level of the dentate nucleus from the subcortical white matter; and the posterior border of the cerebellar cortex is separated on an average of $15.4 \mathrm{~mm}$ from the subcortical white matter.

relations with the deep cerebellar nuclei and with the cortex are more constant. The cerebellar peduncles are connected to the white matter within the ventral and posterolateral aspects of the cerebellum; the superior cerebellar peduncle follows an ascendant trajectory to the mesencepahlon, its tract fibers run from the posterolateral segment of the hemisphere to the superior pole of the dentate nucleus, bordering the lateral aspect of the ventricle roof and medially relating to the superior medullary velum, their straight up bundles are always medial to the dentate nucleus and located in the median zone. The middle cerebellar peduncle has the widest posterolateral projection and it is almost always located in the paramedian zone; it follows a descendent course from the pons. The fibers of the middle cerebellar peduncle can be divided into superior, middle, and inferior. The superior part of the fibers crosses the inferior third of the superior peduncle and runs alongside the median aspect of the dentate nucleus. The middle part of the fibers course posterolaterally alongside the lateral segment of the dentate nucleus around the hemisphere. The inferior tract fibers of the middle cerebral peduncle follow a descendent course and are closely related to the fibers of the inferior cerebellar peduncle at the rostral pole of the dentate nucleus. The inferior cerebellar peduncle ascends alongside the lateral recess and floor of the fourth ventricle with most of its fibers distributed mainly to the rostral pole of the dentate nucleus, these tract fibers are medially related to the dentate nucleus and are mainly located in the median zone. There is an extraordinary medical significance attached to the nuclei of the cerebellum and, among these, particularly to the dentate nucleus ${ }^{3}$. The dentate nucleus is the most lateral nucleus of the cerebellum and it is located in the median zone of the hemisphere. The high frequency, in which the cerebellum is operated, exposing the cerebellar hemispheres, increases the importance of thorough understanding of anatomical and functional features of the cerebellum and their relationship with the deep nucleus ${ }^{8,10}$.

The suboccipital and supracerebellar approaches have been used for lesions in the suboccipital hemispheres and vermis and they have also been adapted for lesions located in the quadrigeminal cistern. In planning operative strategies to tumors of the cerebellum, arteriovenous malformations (AVMs) and other pathologies, it is helpful to consider operative landmarks for localizing avoidable structures ${ }^{10-13}$. If we examine the suboccipital surface of the cerebellum carefully, the best anatomic landmarks are the tonsils, uvula, and middle line $\mathrm{e}^{11}$. The lateral border of the dentate nucleus is separated on an average of $26 \mathrm{~mm}$ from the lateral border of the cerebellum, $23 \mathrm{~mm}$ from the posterior border of the cerebellum and $25 \mathrm{~mm}$ from the posterolateral angle. Therefore, these parameters are actually the medial and posterior limits of the resection and they are easily intraoperatively identified. If a line is traced from the posterosuperior angle of the uvula to the posterior part of the dentate nucleus, there is an average distance of $16 \mathrm{~mm}$ and with $38^{\circ}$ of separation from the middle line (range - from 30 to 42 grades), almost the entire dentate nucleus will stay above and medial to this line.

The best anatomic landmark for the superior limit of the removal is the tonsil and the telovelotonsillar cleft. Also, the dentate nucleus is approximately situated, lateral from the middle line at the level of the posterosuperior angle of the uvula. However, during the resection, only the inferior pole of the tonsil is well-visualized. The inferior pole of the tonsil is separated 
on an average of $19 \mathrm{~mm}$ from the basal surface of the dentate nucleus, and the tonsil has a superolateral implantation base that is at the middle level of the dentate nucleus. When viewed from its medial aspect, the lateral border of the dentate nucleus is separated on an average of $19 \mathrm{~mm}$ from the middle line, and the basal surface of the dentate nucleus is located at the telovelotonsillar cleft. Thus, $19 \mathrm{~mm}$ from the middle line is actually the middle limit of the hemispheric resection.

Difficulty on performing a tentorial surface resection is evident. Useful landmarks to be followed during this stage of surgery are the fissures and the vermis. The dentate nucleus is located anteriorly to the tentorial fissure and the lateral border of the nucleus is separated on an average of $18.5 \mathrm{~mm}$ from the middle line. The nucleus is located at the junction of the upright surface with the flat one. The distance from the dentate nucleus to the level of the tentorial surface is approximately $17 \mathrm{~mm}$.

In conclusion, the thorough knowledge of cerebellum anatomy has a tremendous neurosurgical importance. When dealing with the cerebellum, it is judicious to devise in advance a comprehensive plan of surgical approach and exposure that offers adequate response to all of the foreseeable postoperative complications, which may potentially prejudice the patient's optimal outcome.

\section{References}

1. Carpenter MB. Core text of Neuroanatomy. Baltimore: Williams \& Wilkins; 1991.

2. Rhoton AL Jr. Cerebellum and Fourth ventricle. Neurosurgery 2000;47(Suppl):S7-S27.

3. Lang J. Clinical anatomy of the posterior cranial fossa and its foramina. New York: Stuttgart, Georg Thieme; 1991.

4. Machado A. Neuroanatomia Funcional. Estrutura e funções do cerebelo. São Paulo: Atheneu;1981, p. 179-186.

5. Brazis PW, Masdeu J, Biller J. Localization in Clinical Neurology. New York: Little, Brown; 1996. p. 365-379.

6. Rhoton AL Jr. The Posterior Fossa Veins. Neurosurgery 2000;47(Suppl):S69-S92.

7. Mussi A, Rhoton AL Jr. Telovelar approach to the fourth ventricle: microsurgical antomy. J Neurosurg 2000;92:812-823.
8. Rhoton Al Jr. Microsurgical anatomy of posterior fossa cranial nerves. In: Barrow DL (Ed). Surgery of the cranial nerves of the posterior fossa. Neurosurgical topics. Chicago: AANS; 1993: 1-103.

9. Youmans JR. Neurological surgery. Philadelphia:WB Saunders; 1996.

10. Yasargyl MG. Microneurosurgery Sttugart: Gerog Thieme Verlag; 1984.

11. Matsushina T, Fukui M, Inoue T, Natori Y, Baba T, Fujii K. Microsurgical and magnetic resonancia imagen anatomy of the cerebellomedulary fissure and its application during fourth ventricle surgery. Neurosurgery 1992;30:325-330.

12. Holmes $G$. The croonian lectures on the clinical symptoms of cerebellar disease and their interpretation. Lancet 1992;2:59-65,111-115.

13. Yasargyl MG. Microneurosurgery: CNS tumors-surgical anatomy, neurophatology, neuroradiology, neurophisiology, clinical considerations, operability, treatment options. Stuttgart: Georg Thieme; 1994. 